Article

\title{
Hi-Fi Stake Piezo Single Crystal Actuator
}

\author{
Yu Huang ${ }^{1,2, *}$, Shuangjie Zhang ${ }^{2}$ (D), Penghui Wang ${ }^{3}$, Yue Xue Xia ${ }^{2}$, Dian Hua Lin ${ }^{2}$, Kui Yao 4 (i) \\ and Leong-Chew $\operatorname{Lim}^{2,3, *}$ \\ 1 Department of Mechanical Engineering, National University of Singapore, 21 Lower Kent Ridge Road, \\ Singapore 119077, Singapore \\ 2 Microfine Materials Technologies Pte Ltd., 10 Bukit Batok Crescent, The Spire \#06-02, \\ Singapore 658079, Singapore; sjzhang@microfine-piezo.com (S.Z.); yuexue@microfine-piezo.com (Y.X.X.); \\ dhlin@microfine-piezo.com (D.H.L.) \\ 3 Beijing Crystal Valley Technology Co Ltd., Room B101, Zhongguancum Dongsheng Technology Park, No. 66, \\ Xixiaokou Road, Haidian District, Beijing 100192, China; 420973194@163.com \\ 4 Institute of Materials Research and Engineering (IMRE), A*STAR (Agency for Science, Technology and \\ Research), \#08-03, 2 Fusionopolis Way, Innovis, Singapore 138634, Singapore; k-yao@imre.a-star.edu.sg \\ * Correspondence: huangyu@microfine-piezo.com (Y.H.); mmtlclim@microfine-piezo.com (L.-C.L.)
}

Received: 30 July 2018; Accepted: 27 August 2018; Published: 12 September 2018

\begin{abstract}
High fidelity (Hi-Fi) piezoelectric single crystal stake actuators are presented in this work. They are made of multiple rectangular $\mathrm{d}_{32}$ mode lead-based relaxor ferroelectric (notably $\mathrm{Pb}\left(\mathrm{Zn}_{1 / 3} \mathrm{Nb}_{2 / 3}\right) \mathrm{O}_{3}-\mathrm{PbTiO}_{3}$ (PZN-PT) and $\mathrm{Pb}\left(\mathrm{In}_{0.5} \mathrm{Nb}_{0.5}\right) \mathrm{O}_{3}-\mathrm{Pb}\left(\mathrm{Mg}_{1 / 3} \mathrm{Nb}_{2 / 3}\right) \mathrm{O}_{3}-\mathrm{PbTiO}_{3}$ (PIN-PMN-PT)) single crystals bonded along their long edges with the aid of compliant polymeric edge guides into a square or polygonal pipe-like construction. Due to the highly stable engineered domain structure and high piezoelectricity of single crystal active materials, the actuators exhibit large linear displacement responses with negligible $(<1 \%)$ hysteresis. Prototypes of square-pipe stake actuators were first fabricated and their phase transformation curves under different applied voltages, axial compressive loads and temperatures were established. Based on the information obtained, a range of Hi-Fi stake actuators with external square cross-sections of $5 \times 5 \mathrm{~mm}^{2}, 7.5 \times 7.5 \mathrm{~mm}^{2}$ and $10 \times 10 \mathrm{~mm}^{2}$, each of 4 different overall lengths of $15,28,41$ and $54 \mathrm{~mm}$, were further designed and fabricated using either PZN-PT or PIN-PMN-PT single crystals (both with $\mathrm{T}_{\mathrm{RO}} \approx 110-125^{\circ} \mathrm{C}$ ) of $0.4 \mathrm{~mm}$ in crystal thickness. The stroke for the longest stake actuator fabricated $(\mathrm{L}=54 \mathrm{~mm})$ reaches $-58 \mu \mathrm{m}$ at $240 \mathrm{~V}$. The working conditions, over which these Hi-Fi stake actuators remain linear with negligible hysteresis, were established for a total load of up to $10 \mathrm{~kg}$ and use temperature of up to $40{ }^{\circ} \mathrm{C}$.
\end{abstract}

Keywords: piezoelectric single crystal; piezoelectric actuator; low hysteresis; phase transformation

\section{Introduction}

In recent years, lead-based relaxor- $\mathrm{PbTiO}_{3}$ solid solution ferroelectric single crystals, such as $\mathrm{Pb}\left(\mathrm{Zn}_{1 / 3} \mathrm{Nb}_{2 / 3}\right) \mathrm{O}_{3}-\mathrm{PbTiO}_{3}$ (PZN-PT), $\mathrm{Pb}\left(\mathrm{Mg}_{1 / 3} \mathrm{Nb}_{2 / 3}\right) \mathrm{O}_{3}-\mathrm{PbTiO}_{3}$ (PMN-PT) and $\mathrm{Pb}\left(\mathrm{In}_{0.5} \mathrm{Nb}_{0.5}\right) \mathrm{O}_{3}-\mathrm{Pb}\left(\mathrm{Mg}_{1 / 3} \mathrm{Nb}_{2 / 3}\right) \mathrm{O}_{3}-\mathrm{PbTiO}_{3}$ (PIN-PMN-PT), have attracted much attention due to their superior piezoelectric properties compared to $\mathrm{Pb}\left(\mathrm{Zr}_{0.48} \mathrm{Ti}_{0.52}\right) \mathrm{O}_{3}$ (PZT) piezoceramics [1]. It is well known that the strain (or displacement)-electric field (S-E) responses of PZT piezoceramics display obvious hysteresis [2-5]. Large strain hysteresis generates many problems including control complexity and heat generation during operation [6-8]. In contrast, domain-engineered lead-based relaxor-PT piezoelectric single crystals not only have ultrahigh piezoelectric coefficients but also low dielectric loss and negligible S-E hysteresis [1]. They are promising materials for new-generation linear high-performance piezoelectric devices. One such device is a piezoelectric actuator, which finds 
application as micro- and nano-precision positioners in precision machinery, fast-steering platforms for optics and laser technology, active vibration control, etc. [1,9].

In a previous work, a "high fidelity (Hi-Fi) stake" piezoelectric actuator based on $\mathrm{d}_{32}$-mode PZN-5.5\%PT single crystal material has been described [10]. It displays about 30\% larger axial strain with negligible $(<1 \%)$ hysteresis, as opposed to state-of-the-art PZT piezoceramic stacks of comparable length. It also displays sub-nanometer resolution and moderate blocking force.

Under ambient condition, lead-based relaxor-PT single crystals typically exist in the rhombohedral crystal structure. In this state, while displaying extremely high piezoelectric coefficients, they are also relatively soft and may undergo phase transformation at moderately high electric fields, axial compressive stress or temperature, or their combination. When phase transformations occur, there will be an abrupt change in the induced strain with high hysteresis. In addition to large strain non-linearity and large hysteresis, phase transformation also generates internal stresses in the active material, which in turn could promote crack formation and/or propagation leading to reduced lifespan or even device failure. It is thus important to determine the operating parameters over which the strain responses of stake actuators remain linear with negligible hysteresis.

The phase transformation behaviors of stake actuators made of $d_{32}$ mode PZN-5.5\%PT single crystal at different temperatures with increasing applied electric field were reported in [10]. In the said work, the maximum load applied onto the stake actuator was $1 \mathrm{~kg}$. In practical application, in addition to temperature and applied electric field, the actuator could be operated under much higher loads, either in the form of pre-load or added load. This particular issue is addressed in this work with regard to the development of square-pipe "Hi-Fi stake" piezoelectric single crystal actuators for practical implementation.

\section{Experimental}

\subsection{Fabrication of Single Crystal Stake Actuators}

[011]-poled $\mathrm{d}_{32}$-mode single crystals of both binary PZN-PT and ternary PIN-PMN-PT solid solutions with $\mathrm{T}_{\mathrm{RO}} \approx 110-125^{\circ} \mathrm{C}$ have comparable phase transformation properties and piezoelectric strain coefficients $\left(\mathrm{E}_{\mathrm{RO}} \approx 0.9-1.6 \mathrm{kV} / \mathrm{mm} ; \sigma_{\mathrm{RO}} \approx 15-25 \mathrm{MPa}\right.$ and $\mathrm{d}_{32} \approx-1400-1900 \mathrm{pC} / \mathrm{N}$ for both crystal compositions). Both were selected as the material of stake actuators studied in the present work.

A schematic of the construction of the stake actuator is shown in Figure 1a. It has a hollow square-pipe structure (see Figure 1c), made up by bonding 4 identical pieces of above-described PZN-PT or PIN-PMN-PT d $d_{32}$-mode crystals (in grey) with 4 polycarbonate edge guides-cum-stiffeners (in white) alone their long edges by means of non-conductive epoxy (Figure 1a). During the bonding, all the crystals were oriented such that their poling directions all pointed towards the central line of the resultant actuator. The four inner electrode faces were connected together electrically with the aid of conductive epoxy; so were their 4 external electrode faces which were connected electrically by wrapping them with a short length of $\mathrm{Cu}$ mesh (not shown in Figure 1) following by bonding with conductive epoxy. Then, anodized aluminum upper and lower end caps were bonded at both ends of the square-pipe assembly to complete the construction. The finished stake actuators made from the $12 \mathrm{~mm}$ and $25 \mathrm{~mm}$ length crystals measure $15 \mathrm{~mm}$ and $28 \mathrm{~mm}$ in overall length, respectively.

For stakes of $41 \mathrm{~mm}$ and $54 \mathrm{~mm}$ in overall length, a 2-level construction [11] using $25 \mathrm{~mm}$ and $12 \mathrm{~mm}$ long crystals was adopted, as shown in Figure 1b. An intermediate washer was used in this case. The upper and lower square pipes were first fabricated as described previously. They were then bonded onto the intermediate washer with the aid of a specifically designed alignment fixture to ensure that the square-pipe crystal assemblies in both levels were properly aligned to one another. This 2-level approach, instead of a single-length crystal, was adopted for the following reasons: (a) shorter crystals can be used for cost-saving purposes; and (b) it helps to improve the bending strength of the resultant stake [11]. In the 2-level construction, the inner electrode surfaces of all eight crystals were connected via wires with conductive epoxy and to the live lead wire. All the eight external electrode 
faces were then connected together electrically with the use of $\mathrm{Cu}$ mesh wrap as described previously except that in this case the $\mathrm{Cu}$ mesh also serves to cover up the intermediate washer for aesthetic reason. They were further connected to the ground lead wire.

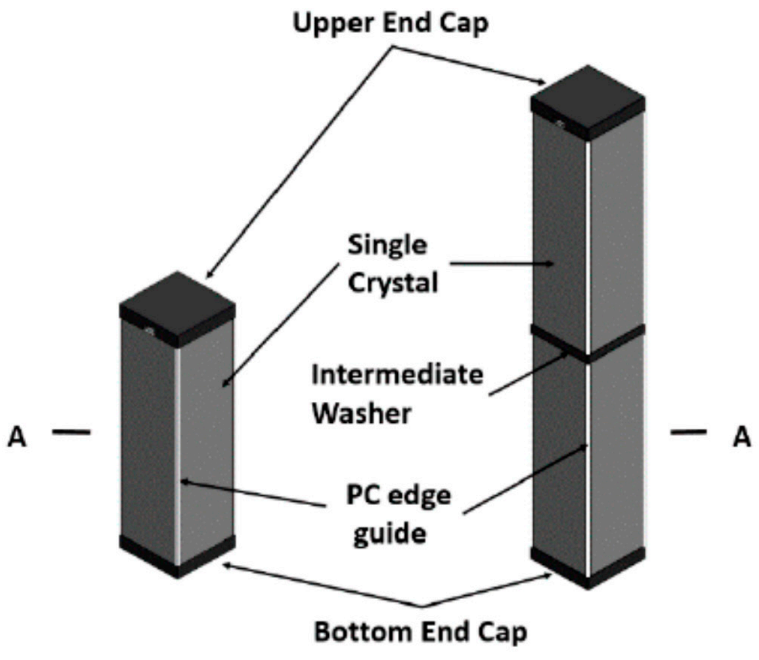

(a)

(b)

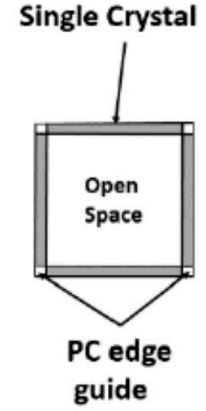

Cross Section A-A

(c)

Figure 1. Sketches showing the construction of square-pipe stake actuators of (a) single-level and (b) 2-level construction. (c) A cross-sectional view across the component crystals.

Figure 2 shows three sets of single crystal stake actuators fabricated in the present work. Each set has respective external sections of $5 \times 5 \mathrm{~mm}^{2}, 7.5 \times 7.5 \mathrm{~mm}^{2}$ and $10 \times 10 \mathrm{~mm}^{2}$ and 4 different overall actuator lengths (L) of $15 \mathrm{~mm}, 28 \mathrm{~mm}, 41 \mathrm{~mm}$ and $54 \mathrm{~mm}$, of which the overall active lengths of the crystals $\left(\mathrm{L}_{\mathrm{ac}}\right)$ are $12 \mathrm{~mm}, 25 \mathrm{~mm}, 37 \mathrm{~mm}$ and $50 \mathrm{~mm}$, respectively. The thickness of the crystals was $0.4 \mathrm{~mm}$.

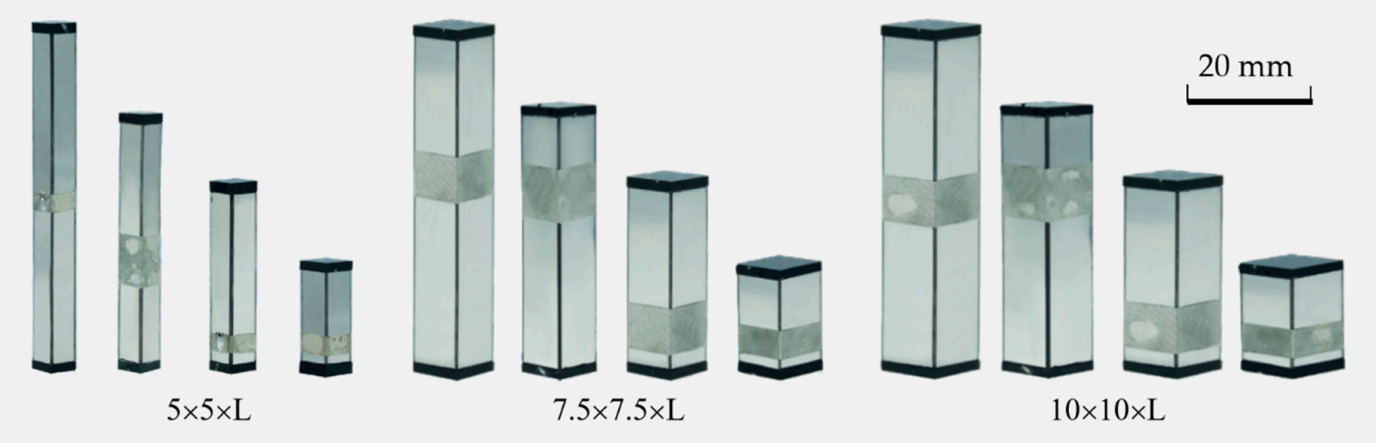

Figure 2. Pictures of a range of stake actuators fabricated. $\mathrm{L}=15,28,41$ and $54 \mathrm{~mm}$. Crystal thickness $=0.4 \mathrm{~mm}$.

\subsection{Displacement Response Measurement Under Controlled Conditions}

The stake actuators studied in this study were of $5 \times 5 \mathrm{~mm}^{2}$ in overall cross-section and $15 \mathrm{~mm}$ in overall length and were made of PZN-PT single crystal $\left(\mathrm{T}_{\mathrm{RO}} \approx 110-125^{\circ} \mathrm{C}\right)$.

Figure 3 shows the test set-up used. It consists of a loading mechanism, comprising a loading adapter (1), clamped firmly onto the dial-gauge probe rod (2), two extension rods (3) which extend through the holes in the stainless steel (S.S.) base plate (12) into the space below, and a lower cross-bar with a hook eye (4) for the weight pan (5) to hang onto (see Figure 3b). The adapter had a flat loading surface which ensures that the compressive load is applied evenly onto the component crystals of 
the stake actuator (6) placed right beneath it. Also included is a lab-built heat insulating box made of polycarbonate (PC) (7), to which heat can be supplied via heating tapes (8; BriskHeat, Columbus, $\mathrm{OH}$, USA: 03106-53) wrapped on the outside. Only the back-half of the heat-insulating box is shown in this figure for clarity sake. Two thermocouples (9) are placed inside the heat-insulating box for temperature monitoring purposes. A strain gage (10; Kyowa, Tokyo, Japan: KFG-02-120-C1-11) is first bonded onto the external electrode face of one of the four component crystals of the stake actuator sample. Then, the actuator sample (6) is positioned to sit right on top of a flat and thick sintered alumina pedestal (11), which serves to spread the applied load over a much larger area of the PC material below. The loading adapter is then carefully lowered until its bottom flat surface rests firmly on the top end face of the actuator. The assembly sits on a thick S.S. base plate (12). In Figure 3b, the S.S. base plate is shown to sit inside the recess of a larger aluminium plate (13) which in turn rests on two layers of thick and flat plank (14), both of which are optional, before they are placed firmly on the top surface of the test bench. Other instruments used but not shown in this figure include: a strain gauge meter (Vishay, Raleigh, NC, USA: P-3500), digital dial gage (Mitutoyo, Kanagawa, Japan: 543-561E), power supply (Eleckro-automatik, Viersen, Germany: PS2084-05B) for the heating tape, and DC power supply (Stanford Research, Sunnyvale, CA, USA: PS350/5000V-05M) for driving the stake actuator.
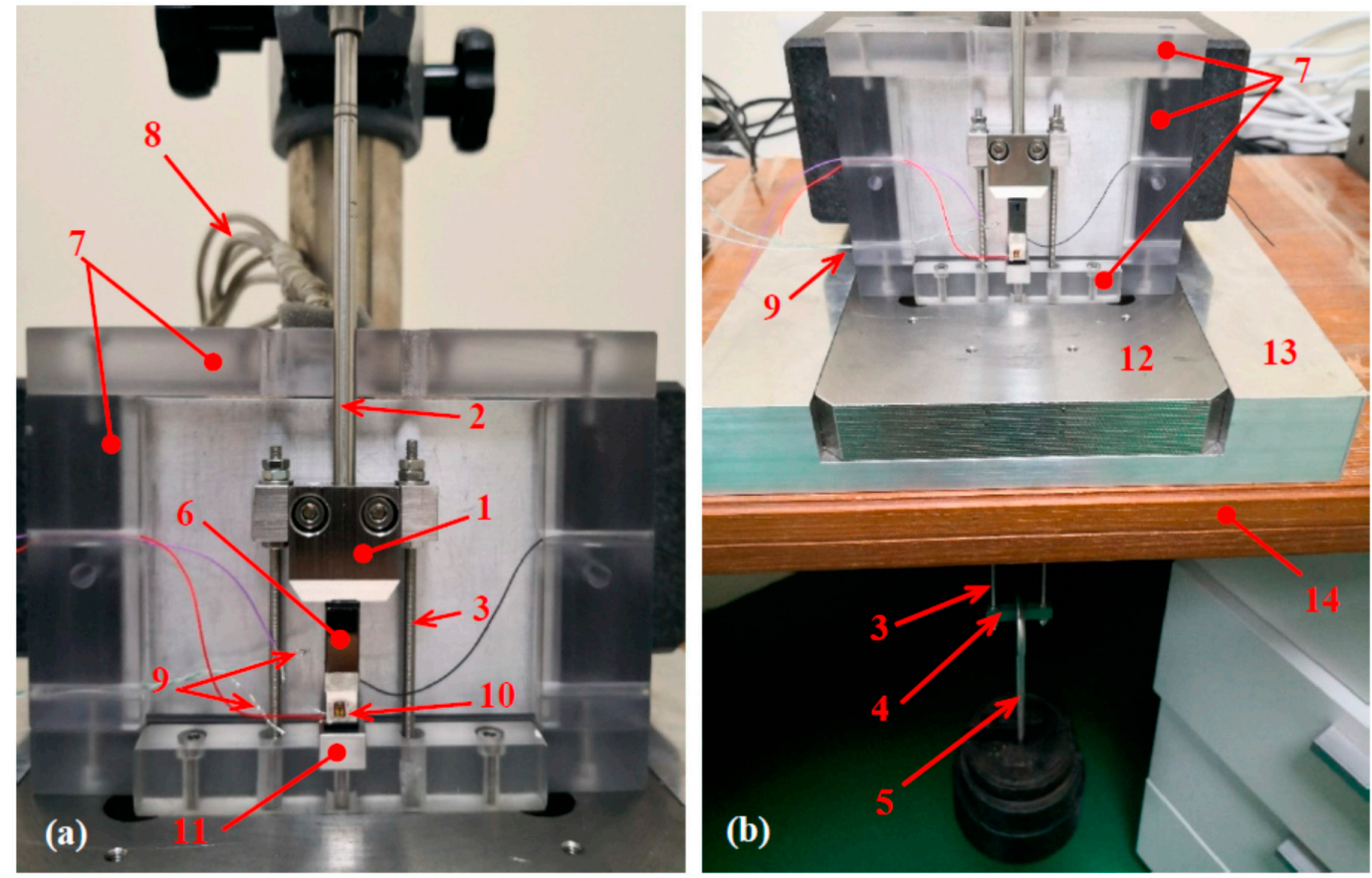

Figure 3. Experiment setup used: (a) single crystal stake actuator sample (6) bonded with a strain gage (10) and loaded via the loading mechanism (1, 2, 3, and 4); (b) application of compressive stress via adding weights onto the weight pan (5). The structure made of translucent polycarbonate is part of the heat insulation box (7) with heating tape (8) wrapped on the outside for tests at elevated temperatures.

A unipolar drive was used to study the displacement responses of the respective stake actuators. In the initial study, a voltage of up to $300 \mathrm{~V}$ was applied using the DC power supply at room temperature under negligible external load condition. During the measurement, the applied voltage was increased in steps of $20 \mathrm{~V}$ each time and the induced displacement was measured by means of the bonded strain gauge. The displacement reading was recorded within $0.5 \mathrm{~s}$ after each voltage step increase. The whole test was completed in less than $30 \mathrm{~s}$.

Typical measurement results obtained are shown in Figure 4. It contains two displacement curves as a function of applied voltage. The upper curve in this figure is that taken at room temperature $\left(22^{\circ} \mathrm{C}\right)$ with no added load (i.e., other than that due to the loading fixture and the light spring load 
of the supplementary dial gage used). Under the said test condition, the displacement response was highly linear with negligible hysteresis. The negative sign of the induced displacement (under positive applied voltage) indicates that the stake actuator actually contracted during the measurement. This is simply the result of $d_{32}$ value being negative for the crystal cut used. For applications in which extension is required, bias drive is recommended. That is, a sufficiently high positive bias voltage should first be applied to the actuator. Then, by decreasing the bias voltage (corresponding to increasing negative applied voltage), the actuator will extend instead [10].

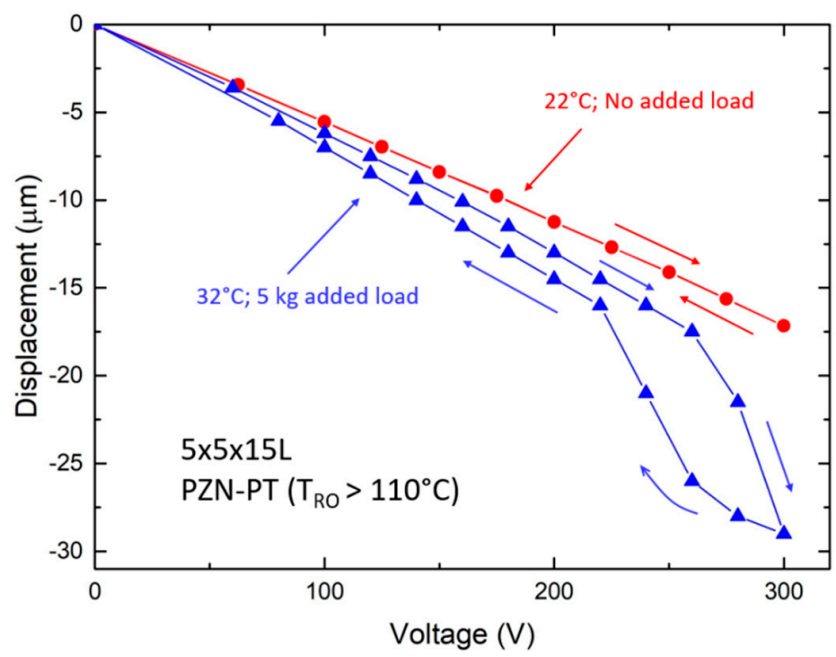

Figure 4. Typical displacement-voltage responses of stake actuators under unipolar drive conditions.

The lower curve in Figure 4 gives the displacement response of the same stake sample but tested at $32{ }^{\circ} \mathrm{C}$ and under $5 \mathrm{~kg}$ added axial compressive load (see the detailed experimental procedure below). In this case, the initial displacement response was linear until the applied voltage reached about $260 \mathrm{~V}$, whereupon there was a perceptible decrease in displacement from 260 to $280 \mathrm{~V}$ and a more abrupt decrease from 280 to $300 \mathrm{~V}$. This sudden dimensional change signifies the occurrence of rhombohedral-to-orthorhombic $(\mathrm{R}-\mathrm{O})$ phase transformation in the component crystals. Judging from the rate of decrease of the displacement at $300 \mathrm{~V}$, the phase transformation event was probably still in process.

On reducing the applied voltage from $300 \mathrm{~V}$, the initial rate of increase of the displacement was higher than the initial rate of decrease in the voltage increasing phase, suggesting that the reverse $\mathrm{O}-\mathrm{R}$ phase transformation could have started early in the reversed voltage cycle. This reverse phase transformation process became more pronounced when the voltage was reduced to $260 \mathrm{~V}$ and below. The component crystals almost reverted back to their original rhombohedral state when the applied voltage was decreased to $220 \mathrm{~V}$. From this voltage to zero voltage, the displacement response of the stake actuator corresponded more to that displayed by the rhombodedral crystal but with obvious hysteresis due possibly to the delayed transformation behavior of the remnant O-phase in the crystals. The stake actuator reverted to original zero displacement state when the applied voltage was reduced to nil.

Comparing the two displacement responses shown in Figure 4, it is obvious that when phase transformation occurs during operation of the stake actuator, the displacement response will no longer be linear and is accompanied by large strain hysteresis. Phase transformation during operation of stake actuators should thus be avoided if it is to display linear, non-hysteretic displacement behavior.

\subsection{Phase Transformation Curve Measurement}

The stake actuators studied in this work were of $5 \times 5 \mathrm{~mm}^{2}$ in overall cross-section and $28 \mathrm{~mm}$ in overall length, and were made of PIN-PMN-PT single crystal $\left(\mathrm{T}_{\mathrm{RO}} \approx 110-125^{\circ} \mathrm{C}\right)$. For tests at ambient 
temperature, the displacement response of the stake as a function of increased applied voltage was measured first under the light spring load of the dial gage only (i.e., under no added load). The applied voltage was increased in small steps as described previously until an abrupt change in displacement was noted, corresponding to the occurrence of $\mathrm{R}-\mathrm{O}$ phase transformation of the component crystals. After which, the voltage was decreased gradually to zero and sufficient time was allowed for the displacement of the stake to return to nil. Then, a certain added load was applied onto the stake actuator via the weight pan and the above displacement measurement was repeated. The above test scheme was repeated until the added load almost reached the zero-field transformation load of the stake.

For tests at elevated temperatures, the stake actuator was placed inside the heat-insulating box. Two thermocouples were placed at both ends of the actuator to confirm that the temperature inside was uniform. After the desired temperature was reached and was further allowed to stabilize for about $30 \mathrm{~min}$, the displacement response with increasing applied voltage of the stake actuator sample was taken, initially under no added load condition and then at higher and higher added loads until it approached the transformation load (@nil voltage) at the set test temperature.

The above tests were then repeated at the next higher temperature. The maximum test temperature used was $45^{\circ} \mathrm{C}$. The maximum added load was about $16 \mathrm{~kg}$ at ambient temperature and $11 \mathrm{~kg}$ at $45^{\circ} \mathrm{C}$. From the above-described exhaustive tests, the transformation curves of $\mathrm{d}_{32}$ mode PZN-PT and PIN-PMN-PT crystals (both with $\mathrm{T}_{\mathrm{RO}} \approx 110-125^{\circ} \mathrm{C}$ ) were determined and plotted.

\subsection{Displacement Resolution Check}

The displacement resolution of the stake actuator was measured by means of laser scanning vibrometry (Polytec, Waldbronn, Germany: OFV 3001S \& 056) under AC drive condition at $200 \mathrm{~Hz}$. A stake actuator sample with $\mathrm{L}=28 \mathrm{~mm}$ was used in this study. It was secured on the test table and the laser beam was positioned onto the top end face of the actuator sample. Rubber blocks were used as dampers to isolate the test set-up from ground vibration. Prior to the actual test, the ground noise was measured. The result showed that the noise was quite small in sub-nano meter range.

\section{Results and Discussion}

\subsection{Determination of Phase Transformation Curves of Single Crystal Stake Actuators}

As mentioned earlier, [011]-poled $\mathrm{d}_{32}$-mode single crystals of both binary PZN-PT and ternary PIN-PMN-PT solid solutions (both with $\mathrm{T}_{\mathrm{RO}} \approx 110-125^{\circ} \mathrm{C}$ ) have comparable phase transformation properties and piezoelectric strain coefficients. They also exhibit similar transformation curves. In what follows, only the results obtained with square-pipe stake actuators made of $d_{32}$-mode PIN-PMN-PT single crystal are reported.

Figure 5 shows the various transformation curves of stake actuators made of $d_{32}$-mode PIN-PMN-PT single crystals $\left(\mathrm{T}_{\mathrm{RO}} \approx 110-125{ }^{\circ} \mathrm{C}\right)$. In this plot, the added load was converted to axial compressive stress experienced by the component crystals and the applied voltage to an applied electric field using known total load bearing area of the crystals and crystal thickness, respectively, so that the results obtained are applicable to stakes made of crystals of different dimensions. This figure shows that the transformation stress increases with decreasing applied electric field and vice versa. Also, at higher temperature, both the transformation stress and electric field decrease accordingly.

In this figure, each curve represents the transformation electric field and transformation compressive stress at a given use temperature. For operating conditions (combinations of applied electric field and axial compressive load) that lie above the transformation curve, the R-O phase transformation will take place in the component crystals. The stake actuator will no longer be linear and would display large strain jump and hysteresis. In contrast, the strain response of the stake actuator remains linear with minimum hysteresis when the stake actuator is operated under conditions below the transformation curve. 
The various transformation curves in Figure 5 show that at a given applied electric field, the maximum operating stress allowed decreases with increasing temperature. Furthermore, at too high applied voltage, the operating temperature and load allowed may be limited. The information contained in this figure is thus very useful for defining the operating conditions of a linear, hysteresis-free stake actuator.

Based on the information provided in Figure 5, the maximum applied voltage of the stake was fixed at $240 \mathrm{~V}$, to enable the various stake actuators fabricated to be used over practical operating conditions, i.e., of up $40{ }^{\circ} \mathrm{C}$ and under a load of up to $10 \mathrm{~kg}$, while maintaining higher strain linearity with negligible hysteresis. This applies to stake actuators driven by $\mathrm{d}_{32}$-mode single crystals of both PZN-PT and PIN-PMN-PT single crystals (both with $\mathrm{T}_{\mathrm{RO}} \approx 110-125^{\circ} \mathrm{C}$ ) fabricated in the present work.

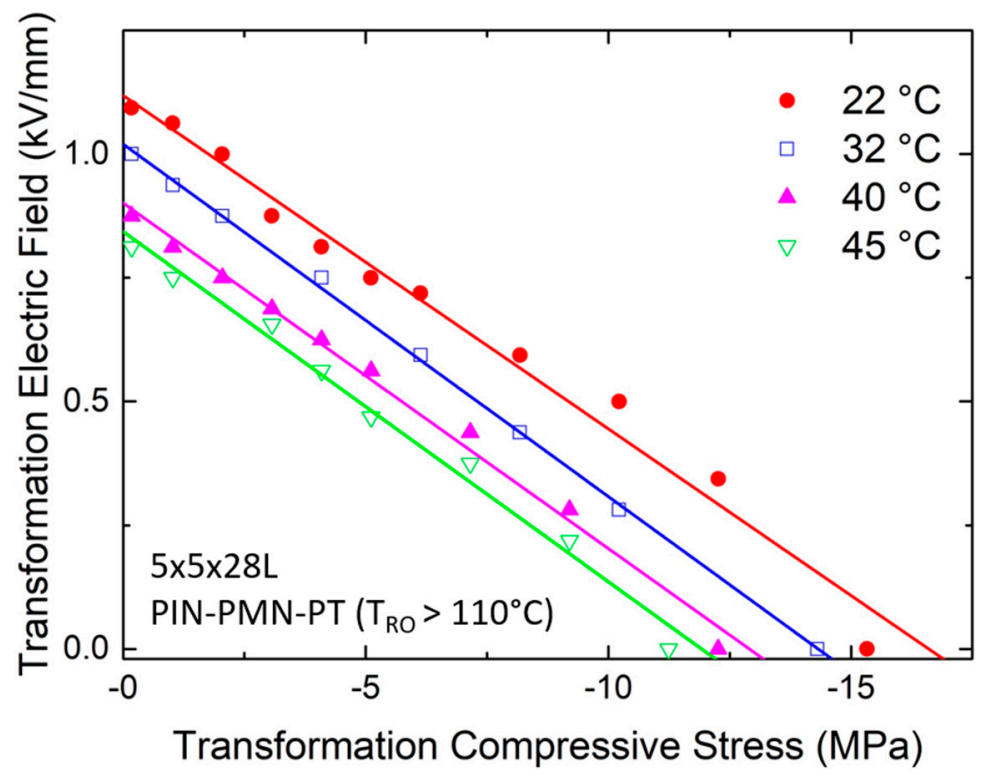

Figure 5. Transformation curves of square-pipe stake actuators made of $\mathrm{Pb}\left(\operatorname{In}_{0.5} \mathrm{Nb}_{0.5}\right) \mathrm{O}_{3}-\mathrm{Pb}\left(\mathrm{Mg}_{1 / 3}\right.$ $\left.\mathrm{Nb}_{2 / 3}\right) \mathrm{O}_{3}-\mathrm{PbTiO}_{3}$ (PIN-PMN-PT) single crystals.

\subsection{Displacement Responses of Hi-Fi Stake Actuators}

With the maximum applied voltage fixed at $240 \mathrm{~V}$, the linear operating ranges of the various stake actuators made in this work are provided in Table 1. The maximum displacement attainable and the calculated stiffness are also listed.

Table 1. Summary of dimensional and performance specifications of 'Hi-Fi stake' actuators.

\begin{tabular}{|c|c|c|c|c|c|}
\hline \multirow{2}{*}{$\begin{array}{c}\text { Stake Dimensions } \\
\mathrm{W}_{1} \times \mathrm{W}_{2} \times \mathrm{L}\left(\mathrm{mm}^{3}\right)\end{array}$} & \multirow{2}{*}{$\begin{array}{c}\text { Stroke }(\mu \mathrm{m}) \\
@+240 \mathrm{~V}\end{array}$} & \multirow{2}{*}{$\begin{array}{l}\text { Stiffness } \\
(\mathrm{kg}-\mathrm{f} / \mu \mathrm{m})\end{array}$} & \multicolumn{3}{|c|}{ Maximum Load Allowed @ +240 V (kg-f) } \\
\hline & & & @ $22{ }^{\circ} \mathrm{C}$ & @ $32{ }^{\circ} \mathrm{C}$ & @ $40{ }^{\circ} \mathrm{C}$ \\
\hline $5 \times 5 \times 15 \mathrm{~L}$ & -14 & 0.37 & \multirow{4}{*}{4} & \multirow{4}{*}{3} & \multirow{4}{*}{2.5} \\
\hline $5 \times 5 \times 28 \mathrm{~L}$ & -29 & 0.20 & & & \\
\hline $5 \times 5 \times 41 \mathrm{~L}$ & -43 & 0.13 & & & \\
\hline $5 \times 5 \times 54 \mathrm{~L}$ & -58 & 0.10 & & & \\
\hline $7.5 \times 7.5 \times 15 \mathrm{~L}$ & -14 & 0.59 & \multirow{4}{*}{6.5} & \multirow{4}{*}{5} & \multirow{4}{*}{4} \\
\hline $7.5 \times 7.5 \times 28 \mathrm{~L}$ & -29 & 0.33 & & & \\
\hline $7.5 \times 7.5 \times 41 \mathrm{~L}$ & -43 & 0.21 & & & \\
\hline $7.5 \times 7.5 \times 54 \mathrm{~L}$ & -58 & 0.16 & & & \\
\hline $10 \times 10 \times 15 \mathrm{~L}$ & -14 & 0.80 & \multirow{4}{*}{10} & \multirow{4}{*}{8} & \multirow{4}{*}{6} \\
\hline $10 \times 10 \times 28 \mathrm{~L}$ & -29 & 0.44 & & & \\
\hline $10 \times 10 \times 41 \mathrm{~L}$ & -43 & 0.29 & & & \\
\hline $10 \times 10 \times 54 \mathrm{~L}$ & -58 & 0.22 & & & \\
\hline
\end{tabular}


Figures 6-8 show, respectively, the displacement responses of the set of four $7.5 \times 7.5 \mathrm{~mm}^{2}$ stake actuators under different loads at ambient $\left(22^{\circ} \mathrm{C}\right), 32{ }^{\circ} \mathrm{C}$ and $40{ }^{\circ} \mathrm{C}$, when driven up to $+240 \mathrm{~V}$. The result shows that there is no phase transformation for all the stake actuators studied under the various operating conditions. The registered stroke (at $240 \mathrm{~V}$ ) varies from -14 to $-58 \mu \mathrm{m}$ for the four different lengths of stake fabricated.

These 3 figures show that the displacements of all the stakes increase slightly with increasing added load. Despite this, the displacement responses remain largely linear with negligible strain hysteresis. That is, they display high fidelity in their displacement (or strain) response over the operating conditions listed in Table 1.

While the stroke is relatively insensitive to the applied load, at a given voltage, the displacement increases with temperature. This is because of the temperature dependence of piezoelectric strain coefficients of lead-based relaxor-PT solid solution single crystals. The present study shows that all the curves in Figures 6-8 can be fitted to the expression:

$$
\Delta \mathrm{L} \approx\{\mathrm{a}+\mathrm{b} \cdot(\mathrm{T}-22)\} \cdot \mathrm{V} \cdot \mathrm{L}_{\mathrm{ac}}
$$

where $\Delta \mathrm{L}$ is the displacement in $\mu \mathrm{m}, \mathrm{T}$ the temperature in ${ }^{\circ} \mathrm{C}, \mathrm{V}$ the applied voltage in volt, $\mathrm{Lac}$ the active length of the actuator in $\mathrm{mm}$; and $\mathrm{a}=4.8 \times 10^{-3}$ and $\mathrm{b}=7 \times 10^{-5}$ in Equation (1). For the three sets of stake actuators shown in Table $1, \mathrm{~L}_{\mathrm{ac}}=(\mathrm{L}-3)$ for $\mathrm{L} \leq 28 \mathrm{~mm}$ and $\mathrm{L}_{\mathrm{ac}}=(\mathrm{L}-4)$ for $\mathrm{L} \geq 41 \mathrm{~mm}$, corresponding to single-level and 2-level stake constructions, respectively, where the length differential $\left(\mathrm{L}-\mathrm{L}_{\mathrm{ac}}\right)$ gives the total length of the inactive components in the various stakes. This equation can be used as a guide to estimate the displacement of the actuator under various temperatures and applied voltages.

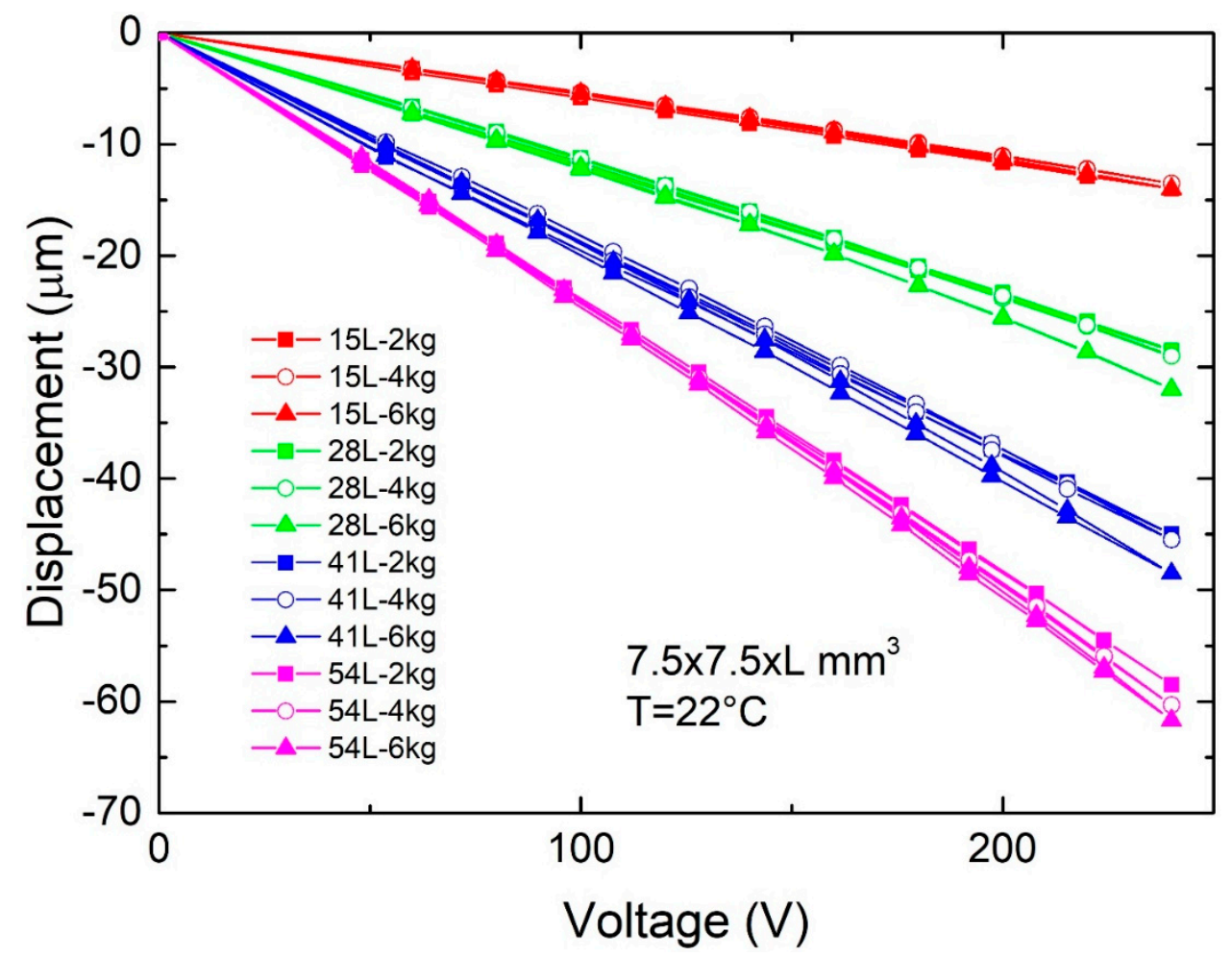

Figure 6. Displacement responses at $22{ }^{\circ} \mathrm{C}$ of square-pipe stake actuators of $7.5 \times 7.5 \mathrm{~mm}^{2}$ overall cross-section and 4 different overall lengths $(\mathrm{L}=15,28,41$ and $54 \mathrm{~mm}$ ) under different axial loads. The applied voltage was increased to the maximum of $240 \mathrm{~V}$ at a rate of $20 \mathrm{~V}$ per $0.5 \mathrm{~s}$ interval and then reduced to nil voltage at the same rate. 


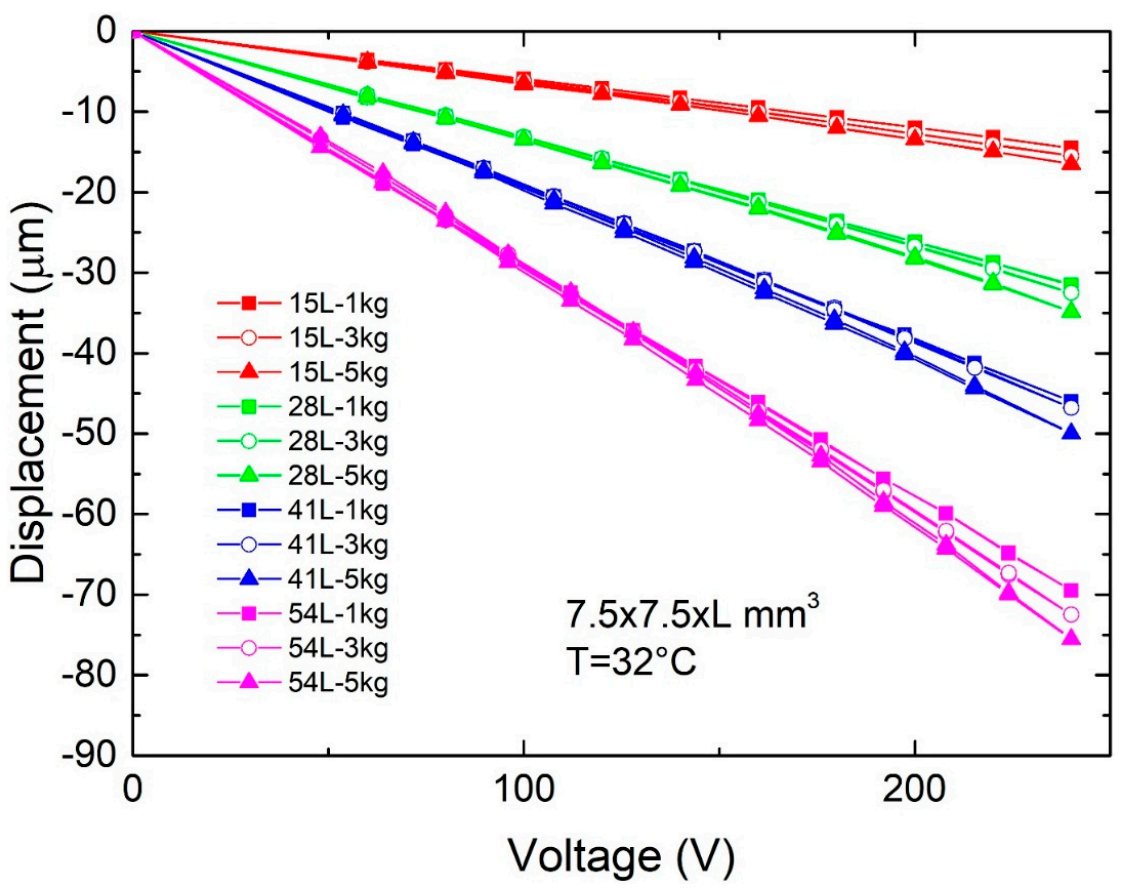

Figure 7. Same as Figure 6 but tested at $32{ }^{\circ} \mathrm{C}$.

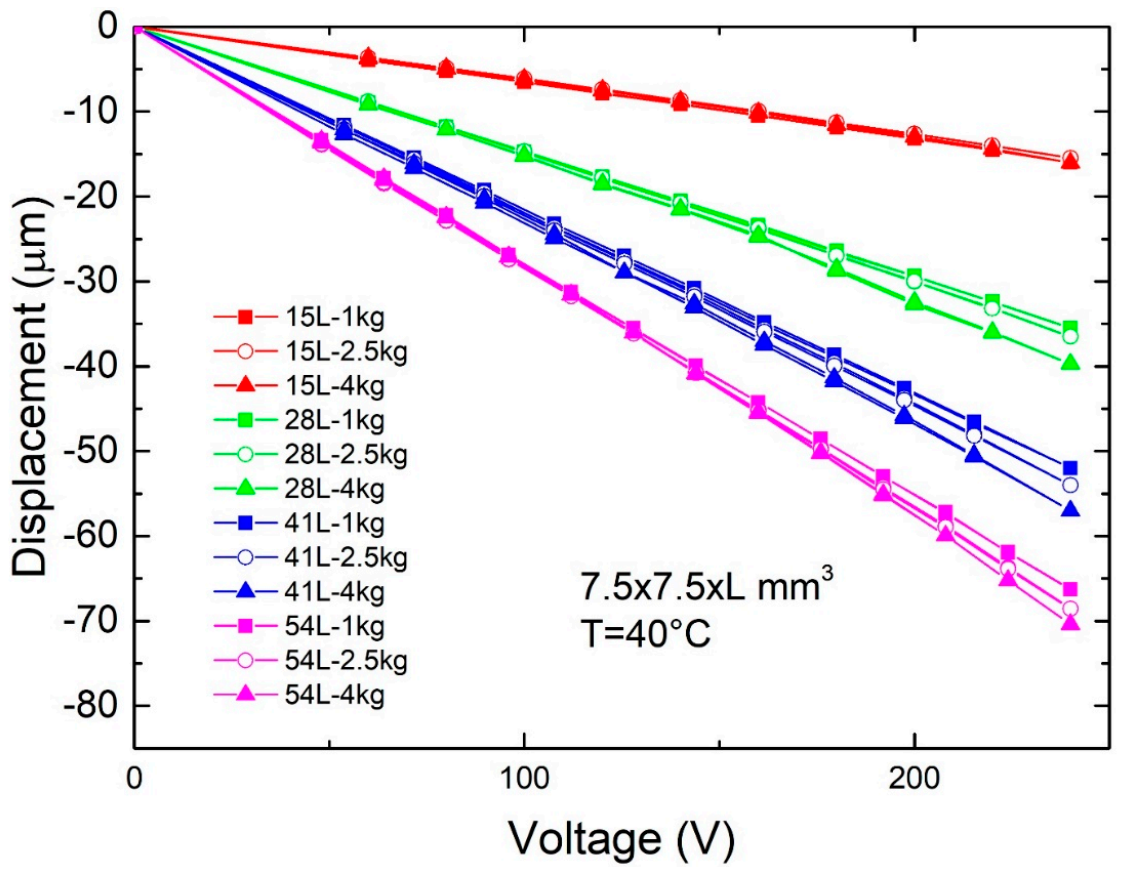

Figure 8. Same as Figure 6 but tested at $40^{\circ} \mathrm{C}$.

As mentioned previously, [011]-poled $\mathrm{d}_{32}$-mode single crystals of both binary PZN-PT and ternary PIN-PMN-PT solid solutions having $\mathrm{T}_{\mathrm{RO}} \approx 110-125^{\circ} \mathrm{C}$ have comparable phase transformation and piezoelectric strain coefficients. The present work further shows that stake actuators of identical construction made of $\mathrm{d}_{32}$-mode single crystals of PZN-PT and PIN-PMN-PT exhibit very similar transformation curves and performance characteristics. 


\subsection{Displacement Resolution}

For displacement resolution determination, the AC voltage applied to the actuator was initially increased from $0.1 \mathrm{~V}_{\mathrm{p}}$ to $0.9 \mathrm{~V}_{\mathrm{p}}$ at $0.1 \mathrm{~V}_{\mathrm{p}}$ interval and later at a much smaller interval of $0.01 \mathrm{~V}_{\mathrm{p}}$ from $0.90 \mathrm{~V}_{\mathrm{p}}$ to $0.95 \mathrm{~V}_{\mathrm{p}}$ [9]. The test results are shown in Figure 9. This figure show that the resolution of the actuator is in the nano-meter range, i.e., about $1 \mathrm{~nm}$ in displacement amplitude per $10 \mathrm{mV}_{\mathrm{p}}$ voltage increment. Accordingly, $0.1 \mathrm{~nm}$ resolution may be expected when the DC power supply is controlled to $1 \mathrm{mV}$ or smaller. This fine displacement arises from the intrinsic piezoelectric effect, being the induced relative displacement of the ions in the crystal under the external excitation field.

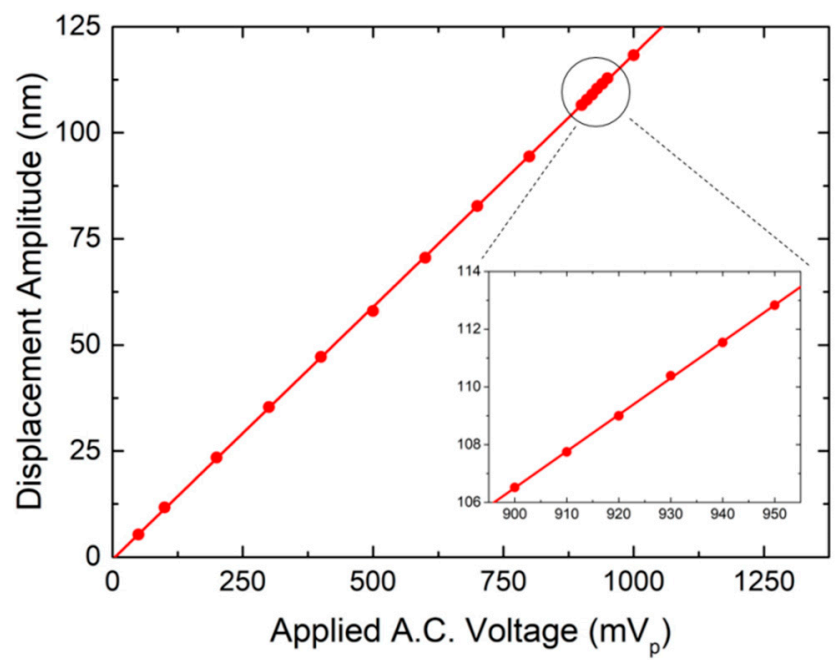

Figure 9. Resolution check for the single crystal stake actuator.

\subsection{Comparison with Commercial Piezoceramic Stacks}

Table 2 compares the performance of the Hi-Fi stake actuator studied in the present work with three state-of-the-art commercial piezoceramic stacks of comparable overall length of $\mathrm{L}=36-41$ $\mathrm{mm}$. The three commercial stacks chosen are: P.I. (P-885.91; Lederhose, Germany) [12], NEC-Tokin (AE0505D44H40DF; Shiroishi, Japan) [13] and Thorlabs (PK4FYP2; Newton, NJ, USA) [14].

This table shows that the Hi-Fi stake actuator not only has comparable stroke but also its displacement response is linear with negligible hysteresis. In contrast, while state-of-the-art PZT multilayer stack actuators are of comparable or larger stroke, their displacement responses are non-linear and of large hysteresis (of $\geq 12 \%$ typically).

Table 2. Performance comparison of $\mathrm{Pb}\left(\mathrm{Zn}_{1 / 3} \mathrm{Nb}_{2 / 3}\right) \mathrm{O}_{3}-\mathrm{PbTiO}_{3}$ (PZN-PT) single crystal 'Hi-Fi stake' and commercial stack actuators of $\mathrm{L}=36-41 \mathrm{~mm}$ [12-14] and with $\mathrm{Pb}\left(\mathrm{Mg}_{1 / 3} \mathrm{Nb}_{2 / 3}\right) \mathrm{O}_{3}-\mathrm{PbTiO}_{3}$ (PMN-PT) single crystal stack [15].

\begin{tabular}{|c|c|c|c|c|c|}
\hline Feature & Hi-Fi Stake & P.I. Stack & NEC-Tokin Stack & Thorlabs Stack & $\begin{array}{c}\text { PMN-PT SC } \\
\text { Stack }\end{array}$ \\
\hline & & $(\mathrm{P}-885.91)$ & (AE0505D44H40DF) & (PK4FYP2) & (Ref. 15) \\
\hline Actuator size $\left(\mathrm{mm}^{3}\right)$ & $5 \times 5 \times 41$ & $5 \times 5 \times 36$ & $5 \times 5 \times 40$ & $5 \times 3 \times 36$ & $3 \times 3 \times 19$ \\
\hline Stroke $(\mu \mathrm{m})$ & $43 @ 240 \mathrm{~V}$ & $38 @ 120 \mathrm{~V}$ & $43 @ 150 \mathrm{~V}$ & $41 @ 150 \mathrm{~V}$ & $21 @ 150 \mathrm{~V}$ \\
\hline Equivalent max. strain (\%) ${ }^{[1]}$ & 0.105 & 0.106 & 0.108 & 0.114 & 0.111 \\
\hline Hysteresis \& linearity ${ }^{[2]}$ & $\begin{array}{c}\text { negligible }(<1 \%) \\
\text { highly linear }\end{array}$ & $\begin{array}{c}15 \% \\
\text { non-linear }\end{array}$ & $\begin{array}{c}12 \% ; \\
\text { non-linear }\end{array}$ & $\begin{array}{c}12 \% ; \\
\text { non-linear }\end{array}$ & $\begin{array}{c}14 \% ; \\
\text { non-linear }\end{array}$ \\
\hline
\end{tabular}

[1] Taken as the ratio of maximum stroke to the overall length of respective actuators; [2] By "linearity" or "non-linearity", we mean here the strain-voltage response when the hysteresis effect is ignored.

Commercial stack actuators are of multilayer construction, in which each PZT ceramic layer could be $0.15 \mathrm{~mm}$ or smaller in thickness, and up to hundreds of layers are possible. As such, they 
are driven at comparatively high electric fields. Domain switching and domain wall movements are the key mechanisms responsible for the induced strain and hence displacement in piezoceramics. These mechanisms dissipate energy, resulting in large hysteresis in the resultant device [3-5].

Also provided in Table 2 (last column) is a multilayer stack actuator made of [001]-poled PMN-PT single crystal reported by Jiang et al. [15]. It is interesting to note that despite having a higher equivalent maximum strain, the PMN-PT single crystal stack also displays considerable strain hysteresis of $>10 \%$. Similar observations were also made by other researchers [16,17]. We shall discuss the plausible reasons below.

\subsection{Large Stroke, Hysteresis-Free Response of Single Crystal Stake Actuators}

The reasons for the large stroke yet linear and hysteresis-free displacement response of the $\mathrm{Hi}-\mathrm{Fi}$ stake single crystal actuators studied have been discussed at length in Ref. [10]. That is, they are the result of the highly stable engineered domains in piezoelectric single crystals and the simple pipe-like construction of the device.

The extremely large piezoelectric coefficients and the extremely low S-E hysteresis of lead-based relaxor-PT solid solution single crystals have been the subject of several investigations [18,19]. Unlike piezoceramics, when the single crystal is poled along certain low-index non-polarization crystal directions, say, along either [001] or [011] crystal directions, very few stable polarization states remain and a high macroscopic symmetry multi-domain structure is formed, i.e., of $4 \mathrm{R}$ or $2 \mathrm{R}$ domain state in [001] and [011]-poled single crystals, respectively, $R$ denoting the room temperature rhombohedral phase. The polarization vectors of the resultant domains in both cases lie at large angles to the applied electric field direction, which is typically the same low-index crystal poling direction. For lead-based relaxor-PT solid solution single crystals of compositions close to the morphotropic phase boundary (MPB), the energy profiles of the various phases are relatively flat, which facilitates polarization rotation in the crystal from the $\mathrm{R}$ phase via metastable phases of comparable energy [20-22]. This results in extremely large shear piezoelectric coefficients and, correspondingly, large longitudinal and transverse piezoelectric coefficients and hence axial strains of [001] and [011]-poled single crystals [23].

In a recent work, $\mathrm{Li}$ et al. [24] reported the results of a phase field study, which shows that this phenomenon is closely linked to the existence of polar nano-regions in lead-based relaxor single crystals. At temperatures above about $120 \mathrm{~K}$, these polar nano-regions would line up to lower the strain gradient and elastic energy in the crystal with their polarization vectors lying at large angles to the applied electric field. The said colinear configuration of polar nano-regions, together with the relatively flat energy profiles of the various phases in both the polar nano-regions and the ferroelectric matrix phase of near MPB composition, gives rise to an abrupt increase in the transverse dielectric permittivity and piezoelectric shear coefficients of the crystal. For [001] and [011] poled domain-engineered relaxor-PT single crystals, this not only leads to large longitudinal and transverse strains via easy polarization rotation but also the induced piezoelectric effect is nonhysteretic [24]. Their experimental results further showed that the said phenomenon accounts for close to $50-80 \%$ of the piezoelectric coefficients at room temperature.

It should be stressed that the large angular difference of the polarization vectors between adjacent domains and their high symmetry deposition make the engineered domain structure highly stable against domain switching and domain wall movement even at an applied electric field close to the transformation field of the crystal. All these account concertedly for the large but nonhysteretic longitudinal and transverse strains in [001] and [011]-poled lead-based relaxor-PT solid solution single crystals $[18,19,24]$.

Another important reason of the hysteresis-free strain behaviors of the stake single crystal actuator is its very simple construction. As described above, attempts had also been made by contemporary researchers to fabricate multilayer stack actuators from domain-engineered single crystals [15-17]. However, strain hysteresis was again noted in the fabricated single crystal stacks, as evident in Table 2. 
Two reasons may account for the unexpectedly large strain hysteresis displayed by the single crystal stacks. First, thin [001]-poled PMN-PT single crystals were used in the quoted studies [15-17]. This crystal has lower transformation properties compared with PZN-PT and PIN-PMN-PT single crystals used in the present work. Even at $150 \mathrm{~V}$, the applied electric field could be quite close to the phase transformation field of the PMN-PT crystals used. It is thus possible that local phase transformation could have occurred in the component crystals. Second, since strain hysteresis persists even at lower applied voltages [15], the complex structure of the single crystal stack actuator with many intermittent piezoelectric and nonpiezoelectric layers may also play a role. Structurally, the nonpiezoelectric component in the stack will produce a constraint effect on the responding piezoelectric components. For instance, Feng et al. [16] noted that the electrodes in between the crystals produce a clamping effect on the piezoelectric material, reducing its piezoelectric response. The said constraint effects introduce internal stresses and strains in the device during operation which is a source of mechanical strain hysteresis. As similar mechanical constraints also present in multilayer piezoceramic stacks, this may partly account for the high S-E hysteresis displayed by the various commercial stacks in Table 2.

The Hi-Fi stake actuators studied in the present work are constructed by bonding 4 rectangular [011]-poled PZN-PT or PIN-PMN-PT single crystals into a square-pipe construction with soft and compliant polycarbonate edge guides, which help to simplify the fabrication process. Such a construction minimizes the number of epoxy joints in the device. This, together with the relatively soft edge guides, enables the crystals to deform freely under the influence of the external field, thus minimizing mechanical hysteresis arising from differential strains in the resultant actuator. In addition, the hollow square-pipe construction also serves two other important functions. Firstly, it helps to limit the volume of the single crystal needed for cost effectiveness. Secondly, despite the edge guides being made of soft PC strips, their use enables the bonded crystals to reinforce and strengthen one another to various degrees which, in turn, greatly increases the bending and twisting strength of the resultant stake actuator.

Lastly, to obtain near-hysteresis-free linear S-E behavior, the operating conditions of the stake actuators must be kept below the transformation field of the active material, taking into consideration the temperature and stress experienced by the component crystals. The use of [011]-poled PZN-PT and PIN-PMN-PT single crystals of relatively high transformation temperatures are critical in this regard.

While the focus of the present work is on cost-effective Hi-Fi Stake piezo single crystal actuators for practical purposes, it should be noted that the performance of the stake actuators depends strongly on the actual operating condition and the volume of the crystal used provided that the occurrence of phase transformation in the crystals during use could be avoided. For instance, at low operating loads (say, $\leq 2 \mathrm{~kg}$ ), the stroke of a similar stake actuator of $28 \mathrm{~mm}$ in length made of PZN-5.5\%PT single crystal can be effectively increased to $37 \mu \mathrm{m}$ when the maximum applied voltage is increased to $300 \mathrm{~V}$ [10]. This gives an equivalent maximum strain of $0.13 \%$, which is $15-30 \%$ larger than that available with state-of-the-art commercial PZT stacks of the same length. When needed, the stroke, operating loads and use temperature of the stake actuator can be increased accordingly by using a larger crystal volume. Furthermore, by using a high-bending-stiffness 2 -level $(2 \times-)$ connector currently being experimented with by us, the stroke and blocking force of the resultant device can be easily doubled (or tripled) [25].

Also being studied is the fatigue property of Hi-Fi Stake piezo single crystal actuators developed in the present work. It should be noted that in addition to the linear and extremely low strain hysteresis characteristics, PZN-PT and PIN-PMN-PT single crystals of $\mathrm{d}_{32}$ mode have extremely low dielectric loss, being $\leq 0.2 \%$ compared with $0.4-0.8 \%$ for hard PZT ceramics and $2-5 \%$ for typical soft PZT ceramics. All these are expected to give rise to improved fatigue properties of the Hi-Fi stake actuator and resultant devices. For instance, $\mathrm{d}_{32}$ mode PZN-5.5\%PT single crystals have been successfully utilized by us to make compact, low frequency (of $15 \mathrm{kHz}$ central frequency) broad band underwater projectors. When operating at full source level at $10 \%$ duty cycle (at $100 \mathrm{~V}_{\mathrm{rms}}$, corresponding to a 
source level of $180 \mathrm{~dB}$ re $1 \mu \mathrm{Pa}$ at $1 \mathrm{~m}$ ), the temperature increase is only a few degrees (i.e., $<5^{\circ} \mathrm{C}$ ) as judged from the capacitance increase of the single crystal [26]. This compares favorably with the severe heat generation for underwater projectors made of PZT ceramics, of which a $50{ }^{\circ} \mathrm{C}-100{ }^{\circ} \mathrm{C}$ temperature increase is common. The results of the various studies described above on Hi-Fi stake piezo single crystal actuators will be published when available.

\section{Conclusions}

"Hi-Fi stake" piezoelectric actuators were fabricated using [011]-poled $\mathrm{d}_{32}$-mode PZN-PT and PIN-PMN-PT single crystals, both with $\mathrm{T}_{\mathrm{RO}} \approx 110-125^{\circ} \mathrm{C}$, by bonding 4 identical crystal pieces of either composition with polymer edge guides-cum-stiffeners along their longest edges into a square-pipe structure, and further bonded with top and bottom end caps. A range of stake actuators with external square cross-sections of $5 \times 5 \mathrm{~mm}^{2}, 7.5 \times 7.5 \mathrm{~mm}^{2}$ and $10 \times 10 \mathrm{~mm}^{2}$, each of 4 different overall lengths of $15,28,41$ and $54 \mathrm{~mm}$, were obtained. For stake actuators of $\geq 41 \mathrm{~mm}$ in length, a two-level construction was adopted to enable shorter crystals to be used.

The displacement responses of prototype stake actuators under different axial compressive loads and temperatures were evaluated, from which the phase transformation curves under different operating conditions were established. Based on the phase transformation curves obtained, practical operating conditions over which these stake actuators remain linear with negligible hysteresis were established, for total load of up to $10 \mathrm{~kg}$ and use temperature of up to $40^{\circ} \mathrm{C}$. These Hi-Fi stake linear actuators are ideal for applications involving large axial displacements and low-to-moderate loads under either closed-loop or simple open-loop control drive conditions.

Author Contributions: Conceptualization, Y.X.X., D.H.L., L.C.L. and Y.H.; Methodology, Y.H. and L.C.L.; Crystal preparation, S.Z., and D.H.L.; Device fabrication, P.W. and Y.H.; Experimental investigation, Y.H.; Technical advice and supervision, K.Y. and L.C.L.; Writing-Original Draft Preparation, Y.H.; Editing, K.Y. and L.C.L.; Project Administration, D.H.L. and L.C.L.; Funding Acquisition, nil.

Funding: This research received no external funding.

Acknowledgments: The authors would like to thank Microfine Materials Technologies Pte Ltd. (MMT), Singapore, for the supply of the crystals used in the present work. Sincere thanks also go to the staff of MMT and Beijing Crystal Valley Technology for the technical support rendered.

Conflicts of Interest: The authors declare no conflict of interest.

\section{References}

1. Zhang, S.; Li, F. High performance ferroelectric relaxor- $\mathrm{PbTiO}_{3}$ single crystals: Status and perspective. J. Appl. Phys. 2012, 111, 031301. [CrossRef]

2. Yao, K.; Uchino, K.; Xu, Y.; Dong, S.; Lim, L.C. Compact piezoelectric stacked actuators for high power applications. IEEE Trans. Ultrason. Ferroelectr. Freq. Control 2000, 47, 819-825. [PubMed]

3. Uchino, K.; Hirosc, S. Loss mechanisms in piezoelectrics: How to measure different losses separately. IEEE Trans. Ultrason. Ferroelectr. Freq. Control 2001, 48, 307-321. [CrossRef] [PubMed]

4. Damjanovic, D. Hysteresis in piezoelectric and ferroelectric materials. In The Science of Hysteresis; Elsevier: Amsterdam, The Netherlands, 2005; Volume 3, pp. 337-452.

5. Liu, G.; Zhang, S.; Jiang, W.; Cao, W.W. Losses in piezoelectric materials. Mater. Sci. Eng. R 2015, 89, 1-48. [CrossRef] [PubMed]

6. Senousy, M.S.; Rajapakse, R.; Mumford, D.; Gadala, M.S. Self-heat generation in piezoelectric stack actuator used in fuel injectors. Smart Mater. Struct. 2009, 18, 045008. [CrossRef]

7. Ru, C.; Chen, L.; Shao, B.; Rong, W.; Sun, L. A hysteresis compensation method of piezoelectric actuator: Model, identification and control. Control Eng. Pract. 2009, 17, 1107-1114. [CrossRef]

8. Zhu, W.; Wang, D.H. Non-symmetrical Bouc-Wen model for a piezoelectric ceramic actuator. Sens. Actuators A Phys. 2012, 181, 51-60. [CrossRef]

9. Niezrecki, C.; Brei, D.; Balahrishnan, S.; Moskalik, A. Piezoelectric actuation: State of the art. Shock Vib. Dig. 2001, 33, 269-280. [CrossRef] 
10. Huang, Y.; Xia, Y.X.; Lin, D.H.; Yao, K.; Lim, L.C. Large stroke high fidelity PZN-PT Single-crystal 'Stake' Actuator. IEEE Trans. Ultrason. Ferroelectr. Freq. Control 2017, 64, 1617-1624. [CrossRef] [PubMed]

11. Xia, Y.; Goh, H.N.; Lin, D.H. Cost-Effective Single Crystal Multi-Stake Actuator and Method of Manufacture. U.S. Patent No.U.S.9,673,374B2, 6 June 2017.

12. PI. PICMA ${ }^{\circledR}$ Piezo Linear Actuators. Available online: http://www.piceramic.com/products/picmamultilayer-piezo-actuator.html (accessed on 14 August 2018).

13. Tokin. Multilayer Piezoelectric Actuator. Available online: https://www.tokin.com/english/product/pdf_ dl/multilayerpiezoelectricactu.pdf (accessed on 14 August 2018).

14. Thorlabs. Discrete Piezoelectric Stacks, $5.2 \mu \mathrm{m}$ to $100.0 \mu \mathrm{m}$ Travel. Available online: https://www.thorlabs. com/newgrouppage9.cfm?objectgroup_id=8040 (accessed on 14 August 2018).

15. Jiang, X.; Rehrig, P.W.; Luo, J.; Hackenberger, W.S.; Zhang, S.; Shourt, T.R. Low voltage single crystal actuators. Proc. SPIE 2006, 6170, 61700G.

16. Feng, Z.; Li, H.; Luo, H.; Jin, W. High electric-field-induced strain behavior of single-crystal $\mathrm{Pb}\left(\mathrm{Mg}_{1 / 3} \mathrm{Nb}_{2 / 3}\right) \mathrm{O}_{3-x} \mathrm{PbTiO}_{3}$ multilayer piezoelectric actuators. J. Electron. Mater. 2005, 34, 1035-1039. [CrossRef]

17. Jiang, X.; Cook, W.B.; Hackenberger, W.S. Cryogenic piezoelectric actuator. Proc. SPIE 2009, 7439, $74390 Z$.

18. Feng, Z.; He, T.; Xu, H.; Luo, H.; Yin, Z. High electric-field-induced strain of $\mathrm{Pb}\left(\mathrm{Mg}_{1 / 3} \mathrm{Nb}_{2 / 3}\right) \mathrm{O}_{3-x} \mathrm{PbTiO}_{3}$ crystals in multilayer actuators. Solid State Commun. 2004, 130, 557-562. [CrossRef]

19. Zhang, S.; Sherlock, N.P.; Mayer, R.J., Jr.; Shrout, T.R. Crystallographic dependence of loss in domain-engineered relaxor-PT single crystals. Appl. Phys. Lett. 2009, 94, 162906. [CrossRef] [PubMed]

20. Fu, H.; Cohen, R.E. Polarization rotation mechanism for ultrahigh-electromechanical response in single-crystal piezoelectrics. Nature 2000, 403, 281-283. [CrossRef] [PubMed]

21. Damjanovic, D. Contribution to the piezoelectric effect in ferroelectric single crystals and ceramics. J. Am. Ceram. Soc. 2005, 88, 2663-2676. [CrossRef]

22. Davis, M.; Damjanovic, D.; Setter, N. Electric-field-, temperature- and stress-induced phase transitions in relaxor-ferroelectric single crystals. Phys. Rev. B Condens. Matter 2006, 73, 014115. [CrossRef]

23. Davis, M.; Budimir, M.; Damjanovic, D.; Setter, N. Rotator and extender ferroelectrics: Importance of the shear coefficient to the piezoelectric properties of domain-engineered crystals and ceramics. J. Appl. Phys. 2007, 101, 054112. [CrossRef]

24. Li, F.; Zhang, S.; Yang, T.; Xu, Z.; Zhang, N.; Liu, G.; Wang, J.; Wang, J.; Cheng, Z.; Ye, Z.-G.; et al. The origin of ultrahigh piezoelectricity in relaxor ferroelectric solid solution crystals. Nat. Commun. 2016, 7, 13807. [CrossRef] [PubMed]

25. Huang, Y.; Xia, Y.X.; Lin, D.H.; Lim, L.C. High-bending-stiffness connector (HBSC) and high-authority piezoelectric actuators (HAPA) made of such. Actuators 2018, submitted.

26. Lim, L.C.; Zhang, S.; Xia, Y.X.; Lin, D.H.; Goh, N.H.L. $\mathrm{Pb}\left(\mathrm{Zn}_{1 / 3} \mathrm{Nb}_{2 / 3}\right) \mathrm{O}_{3}-\mathrm{PbTiO}_{3}$ single crystal and device development. J. Adv. Dielectr. 2014, 4, 1350026. [CrossRef] 